\title{
31st Meeting of the \\ Canadian Congress of Neurological Sciences
}

\author{
London, June 25-29, 1996
}

Preliminary Program

\begin{abstract}
- Plenary Sessions - Platform sessions - Meet the Expert Breakfasts: Neurology, Neurosurgery, Child Neurology $\bullet$ Comprehensive Exhibition of the most current pharmaceutical products and medical equipment - Forum on Fellowship Training programs - Dedicated Poster Viewing sessions \& Interactive Posters - Welcome Reception - Evening at Wonderland Gardens, home of Guy Lombardo - Neuroscience Challenge Race: War Canoes on the Thames - Evening of Shakespeare at Stratford
\end{abstract}

\section{Pre-Congress Symposia}

1. Child Neurology Day: Focal Epilepsies

2. Modern Management of Stroke

3. Surgical Approaches to Parkinson's Disease

4. The Role of Stereotactic Radiosurgery in Cerebral Tumors

5. Epilepsy Rounds - Illustrated Cases

\section{Neurobiology Review 1996:}

Review of the Current Cellular and Molecular Biology Understanding of Neurological Disorders including Cerebral Ischemia, Migraine, Parkinson's Disease and Pain

\section{Courses}

1. Surgical Management of the Occipitocervical Junction

2. Neurosurgery: Neuroimaging - New Concepts

3. Clinical Neurophysiology of Critical Care

4. Motor Neuron Disease

5. Update in Neuropathology for Neurologists and Neurosurgeons

6. History of Neuroscience

7. Medical Management of Headache

8. Child Neurology - Neurodegenerative Disease

\section{Special Guests}

Child Neurology Lecturer

Hugo Moser, Baltimore

Neurophysiology Lecturer

Penfield Lecturer

Michael Aminoff,

San Francisco

Richardson Lecturer

Royal College Neurology

Roval College Neurosurgery
M. Gazi Yazargil, Little Rock

Richard Frackowiak, London, England

Peter J. Goadsby, London, England

Alan Crockard, London, England

\section{Special Feature}

\section{Leonardo Da Vinci - The Search for the Soul}

Rolando Del Maestro in conjunction with the London Regional Art Gallery has organized this special exhibition which will open in conjunction with the 1996 meeting of the CCNS. The majority of the exhibition will be based on $\mathrm{Dr}$. Del Maestro's extensive library of Vinciana with additional material being provided by a number of other private and public collections.

For additional information contact:

The Canadian Congress of Neurological Sciences

Suite 810, 906 - 12 Avenue SW

Calgary, Alberta, Canada T2R 1K7

Tel: (403) 229-9544 Fax: (403) 229-1661 